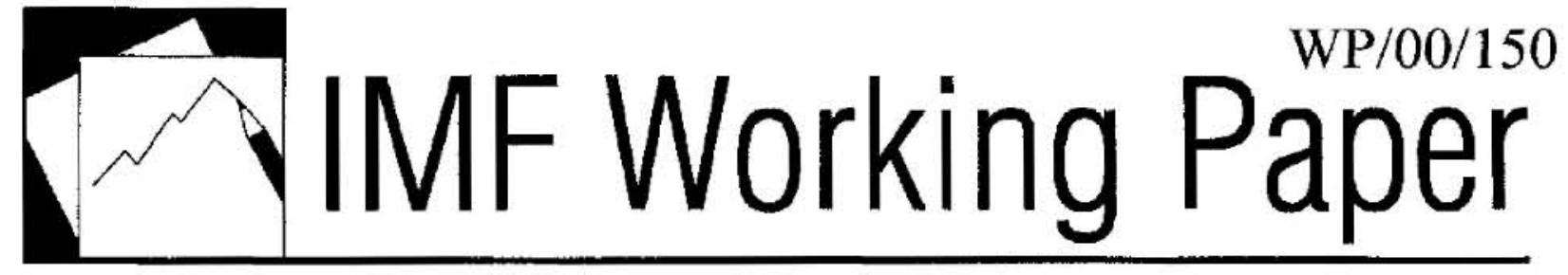

\title{
Should Subsidized Private Transfers Replace Government Social Insurance?
}

Ralph Chami and Connel Fullenkamp 


\title{
IMF Working Paper
}

IMF Institute

\section{Should Subsidized Private Transfers Replace Government Social Insurance?}

\author{
Prepared by Ralph Chami and Connel Fullenkamp ${ }^{1}$
}

Authorized for distribution by Samir El-Khouri

August 2000

\begin{tabular}{l} 
Abstract \\
\begin{tabular}{|l|} 
The views expressod in this Working Paper are those of the author(s) and do not necessarily \\
represent those of the IMF or IMF policy. Working Papers describe research in progress by the \\
author(s) and are published to elicit comments and to further debate.
\end{tabular} \\
\hline
\end{tabular}

Private transfers between individuals or through organized charities are increasingly viewed as an alternative for government social insurance programs. This paper models the incentive effects of government subsidized private transfers and finds that while there is a significant welfare benefit to subsidizing private transfers, there is also a significant welfare cost to this policy. It is shown analytically, as well as through simulations, that the optimal subsidy to private transfers is positive for a wide range of parameter values. This result indicates that subsidized private transfers in net terms are welfare enhancing.

JEL Classification Numbers:D64, D82, H21

Keywords: Altruism, charity, asymmetric information, social insurance, nonmarket transfers, non-governmental organizations (NGOs)

Author's E-Mail Address: rchami@imf.org

${ }^{1}$ Ralph Chami is an economist in the IMF Institute. Connel Fullenkamp is Visiting Professor, Department of Economics, Duke University. The authors wish to thank Richard Arnott, Steve Davis, Samir El-Khouri, David Friedman, Mohsin Khan, Shelly Lundberg, Fabrizio Perri, Michael Waldman, Eda Zoli, and participants at the 1998 Northwestern University/University of Chicago Joint Center for Poverty Research September Institute. 


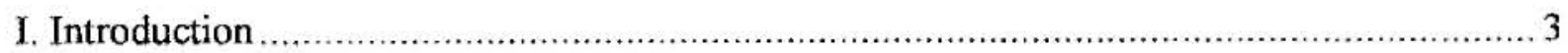

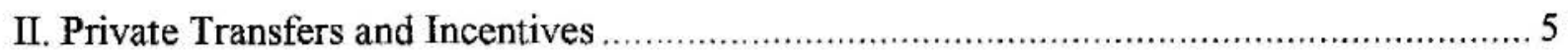

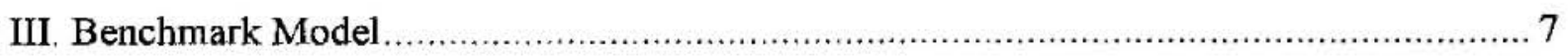

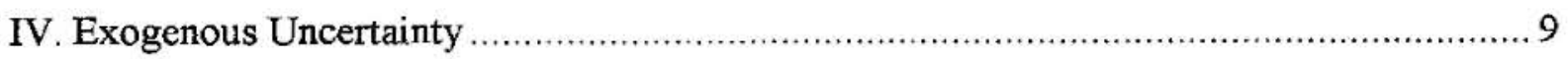

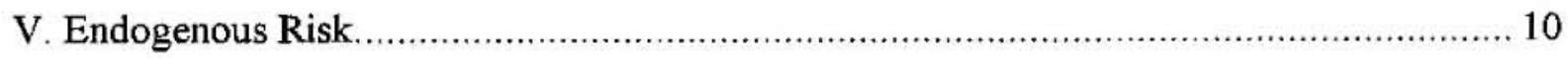

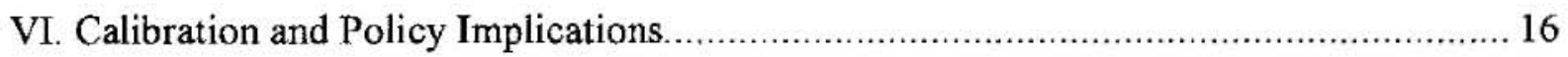

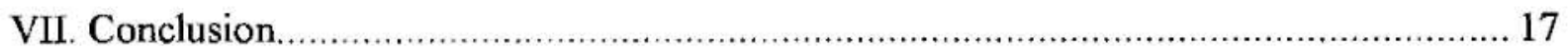

Figures

la. Market Equilibrium With Moral Hazard ......................................................... 20

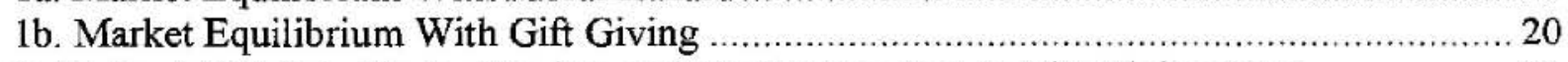

2. Optimal Gift Subsidy as Altruism and Market Reaction to Gift Giving Vary ................. 21

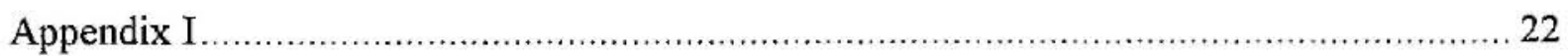

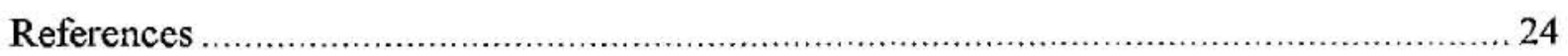




\section{INTRODUCTION}

Until recently, reforming government social insurance was considered virtually unthinkable in most industrialized nations. But several developments have combined to make this not only possible but likely. First, the rising costs of social insurance programs have recently contributed to fiscal problems in most industrialized nations. For example, many EU members had difficulty meeting the requirements for European Monetary Union (EMU) because their debt-GDP ratios, which included borrowing to finance social insurance programs, exceeded the allowable limits ${ }^{2}$. In a similar vein, Tanzi (2000) argues that globalization is reducing government's ability to maintain tax funding for social insurance spending. A second development is the increased recognition by the general public of the indirect costs of government social insurance, which include distorted work incentives that lead to high and persistent unemployment. Finally, efforts to reduce government involvement in other areas of the economy have generally lead to faster economic growth, lower prices, and better quality of goods and services in the deregulated industries. This suggests that reforming government social insurance could lead to similar improvements in service.

The above developments not only indicate that reforms will occur, but they also point in the direction of increased reliance on the existing system of private, nonmarket social insurance. In most developed nations, private charitable giving is already large and pervasive. Much if not most of these transfers are intermediated through non-governmental organizations ${ }^{3}$ (NGOs). NGOs have developed an extensive infrastructure for distributing money, goods and services that rivals and in some ways exceeds the government's distribution network. In addition, NGOs compete with one another in terms of efficiency and quality of service in order to attract private donations. Governments may be able to reduce the costs of providing social insurance, without abdicating their responsibility for providing a social safety net, by channeling public social insurance funds through the private system of social insurance--in other words, by subsidizing private transfers.

Many governments already subsidize private social insurance transfers. The US, for example, has long provided a subsidy to private transfers in the form of income tax deductions for individuals. In addition, both federal and state governments provide direct subsidies to NGOs in the form of grants. Given the trend toward privatization and the existing policy of subsidization, a logical question to ask is whether subsidizing private transfers should become the centerpiece of social insurance policy. Should subsidized private transfers replace government transfer programs as the main form of social insurance?

We believe that this question represents a credible policy alternative that merits careful consideration from economists and policymakers. Admittedly, there are several aspects to this

\footnotetext{
${ }^{2}$ See, for example, Kopits (1997).

${ }^{3}$ For the purposes of this paper, NGOs include all private groups who make nonmarket insurance transfers. This includes organizations such as unions, religious groups and service clubs as well as organized charities.
} 
question, and not all of them can be analyzed in a single paper. In this paper, we examine the incentive effects of subsidized private transfers, measured in terms of welfare. We have three reasons for doing so. First, the welfare effects of subsidized private transfers represent costs and benefits that must be weighed along with the monetary costs and benefits of this policy change. Second, understanding the incentive effects of subsidized private transfers helps policymakers choose the optimal rate of subsidy even if the government continues to provide social insurance directly. Finally, we know that government transfer programs affect work incentives, but the effects of subsidized private transfers on the labor market have not been examined. If subsidized private transfers impose significant costs on the labor market, then these costs undermine the purpose of social insurance and could outweigh other benefits from private transfers.

Our analysis identifies both a significant welfare benefit and a significant welfare cost associated with subsidized private transfers. We argue that, on balance, subsidized private transfers are welfare enhancing, provided that the transfers are intermediated through NGOs, and not given directly to the public. In order to make our argument, we first discuss the incentive effects of private transfers. On one hand, previous literature shows that voluntary private transfers are associated with a positive consumption externality, which is not present in government-mandated transfers. We argue that private transfers also induce a negative labor market externality. This externality begets a labor market response that reduces welfare. The analysis of the market's response to private transfers is new to the literature and is one of the major contributions of the paper. The negative labor market externality implies that private transfers impose the same types of indirect costs on the labor market as do public social insurance programs.

Our next step is to develop a model that will enable us to weigh the welfare benefit of private transfers against their cost. We begin with a simple model of altruistic transfers under complete information, then add uncertainty and asymmetric information in separate stages. The fully developed model includes both the positive and the negative incentive effects of transfers and shows how the market reacts to the presence of the private transfers. After each step in developing our model, we derive the social planner's choice of optimal subsidy for private transfers. We show analytically how the optimal subsidy falls when the welfare cost is added to the model, possibly to negative levels that imply an optimal tax. Through simulations, however, we demonstrate that the optimal subsidy is positive and economically significant for a wide range of preference parameters.

In the conclusion, we discuss how NGOs may mitigate the negative effects of private transfers and thus ensure that subsidized private transfers are welfare enhancing. We believe that NGOs are able to use special monitoring and incentive mechanisms that governments cannot take full advantage of. Therefore, if private transfers are directed through NGOs, this would help to ensure that the change from government mandated transfers to subsidized private transfers is welfare enhancing. 


\section{Private Transfers AND INCENTIVES}

The idea that private transfers should be subsidized by the government finds ample support in the literature. In the Handbook of Public Economics, Stiglitz (1987, p. 1035) writes, "Since gift giving increases the utility both of the giver and the receiver, it is doubly blessed in our social welfare function, and the government will seek to encourage it, through a bequest subsidy." The model of private transfers underlying this conclusion views charitable giving as a person-toperson transfer of income. The benefactor makes a transfer either because her utility depends on the recipient's utility, or because the very act of giving provides her with utility. This approach to charitable giving differs from the public-goods approach, which Andreoni (1988) shows to be inconsistent with the empirical facts regarding charitable donations. Nonetheless, both views of charitable transfers conclude that private transfers are underprovided in a competitive equilibrium. Friedman (1988) shows that altruistic private transfers create a consumption externality in that the giver values only the increase in her own welfare, which is dependent on but distinct from the increase in the recipient's welfare. A social planner, on the other hand, sees that transfers raise both persons' utilities and therefore concludes that private transfers are underprovided. The appropriate response to the underprovision, as Stiglitz argues, is for the government to subsidize private transfers. Kaplow (1995) calculates the size of this subsidy under full information.

The above papers supporting the conclusion that private-transfers should be subsidized develop their analyses using a partial equilibrium setting with full information. Introducing risk and uncertainty into the discussion of private transfers is important because private transfers are one way that agents engage in risk-sharing behavior such as insuring one another. Private transfers are often given to victims of natural disasters, for example, to compensate them for the loss of income and possessions. On the other hand, private transfers are also given to compensate people who have low permanent incomes. It is clear, however, that the risk of a natural disaster is not the same as the risk of having a low permanent income. The former risk seems exogenous with respect to individuals' actions (except perhaps to the choice of where to live), while the latter risk depends greatly on the actions of the individual in the labor market. In this paper, we shall refer to the former type of risk as exogenous risk and the latter as endogenous risk. These different types of risk may imply different degrees and forms of risk sharing, from the perspective of a social planner, and hence imply different optimal rates of subsidy for private transfers.

Introducing asymmetric information is also important to the analysis of private transfers, especially given the presence of endogenous risk. Many private transfers take place under asymmetric information. When private transfers are intermediated by charitable organizations such as the Red Cross and the United Way, for example, it is reasonable to believe that the givers cannot observe the actions taken by the recipients. Even when private transfers pass directly from giver to recipient, there may still be asymmetric information. When parents make transfers to adult children to compensate for poor labor market outcomes or liquidity crises, for example, it is also reasonable to expect that parents cannot observe the actions of their children in the relevant markets. It is well known that when a risk being insured against is endogenous in the sense described above, the presence of asymmetric information about the actions taken by the 
insured leads to moral hazard problems. These problems include the Samaritan's Dilemma ${ }^{4}$, in which the recipient takes advantage of the giver by engaging in activities that make recourse to the insurance more likely. A social planner would anticipate these asymmetric information problems and adjust the optimal subsidy accordingly. Bruce and Waldman (1991) as well as Coate (1995) propose that a partial solution to this moral hazard problem is to give in-kind transfers rather than cash transfers. In this way, the giver attempts to restrict the use of the transfer to ways that avoid future recourse to the insurance. Giving food stamps to low-income individuals instead of cash is an example.

Still missing from the literature is an analysis of how private transfers affect the market. Since private transfers change the incentives and constraints that givers and recipients face in the market, they affect economic choices and change market outcomes ${ }^{5}$. Changes in equilibrium prices and quantities affect welfare and with it the social planner's choice of subsidy. In the above example, private transfers' provision of insurance against an endogenous risk leads to a moral hazard problem that alters the recipients' choice of action. Since this action affects (say) the labor market outcome, the labor market will react to the moral hazard by altering equilibrium price and quantity. The change in equilibrium prices and quantities will have direct implications for welfare. One possibility in this situation is that private transfers can actually lower total welfare. But because givers and recipients are price takers, they will not act to change their behavior. Only a social planner, who can change the rate of subsidy to private transfers, can remedy such a situation.

By placing the private transfer decision in a market economy with uncertainty and asymmetric information, we can analyze how private transfers affect the allocation of market risk in the economy, and ask what the optimal subsidy rate is, after the full set of welfare effects are considered ${ }^{6}$. We proceed by introducing the private transfer decision into a model in which the recipients' incomes are random. Private transfers could be motivated by a desire on the part of givers to insure (compensate) recipients against bad realizations of income. When this income risk is exogenous, we show that the conclusions due to Stiglitz, Friedman and Kaplow still hold: private transfers should be subsidized, and the optimal subsidy is the same as in the certainty case.

But the result changes when we add a labor market with moral hazard and endogenize the income risk ${ }^{7}$. We develop a simple model in which recipients work for profit-maximizing firms

${ }^{4}$ See Buchanan (1975) and Bruce and Waldman (1990).

${ }^{5}$ Cutler and Gruber (1996) show empirically that in-kind social insurance benefits affect the market price of private insurance.

${ }^{6}$ Atkinson (1976) considers a similar issue in his model, in which charitable gifts affect recipients' incomes and the "effectiveness" with which charities convert donations into recipient income affects the choice of tax treatment of charitable giving.

${ }^{7}$ Alternatively, we could also use the insurance market, or any market in which information asymmetries are present, to illustrate our argument. See Arnott and Stiglitz (1991). 
whose output is random. Neither benefactors nor firms can observe the work effort of the recipients in the labor market, so that it is not possible for benefactors or firms to contract with the recipients regarding their effort level. Benefactors, wishing to insure recipients against labor market risk because of altruistic preferences, make transfers to the recipients. But recipients will use transfer income to reduce their labor effort, because expending effort gives disutility. As private transfers increase, aggregate labor effort falls and lower output is realized. The market reacts to lower output and profits by altering the wages paid to the recipients in a way that lowers their welfare. In short, private transfers impose a negative externality on the market. The market responds to this externality by shifting some of the costs imposed on it back onto the recipients. A social planner, taking the externality and the market's reaction into account, would not wish to subsidize private transfers as heavily as in the case of exogenous uncertainty. Therefore, we show that the optimal subsidy to private transfers unambiguously falls, relative to the exogenous risk case. The size of the decline in the optimal subsidy depends on the level of altruism and the intensity of the market reaction to private transfers.

The welfare costs imposed by private transfers are familiar to those who study the effects of government social insurance programs. The moral hazard that exists between transfer recipients and employers is the same as the one that exists between social insurance recipients and employers. The positive externality in private transfers, however, generally ensures that the optimal subsidy is positive. In addition, private agencies may have incentive mechanisms available to them that enable them to mitigate the moral hazard problem. To the extent that NGOs are able to do this, it strengthens the case for subsidized private transfers.

\section{BENCHMARK MODEL}

We begin with an economy populated by two types of individuals: benefactors and recipients. Benefactors are paired with recipients, toward whom they feel altruistic. That is, the recipient's utility is an argument in the benefactor's utility function ${ }^{8}$. The recipients' utility is a function only of their own consumption. We assume that altruism is asymmetric only for the sake of clarity. Making altruism reciprocal and symmetric will not change the qualitative results of this and subsequent sections, except for a special case that affects the results of Section $5 .{ }^{9}$

We assume that the benefactor's utility function is additively separable and is given by

$$
U_{b}\left(y_{b}, u_{r}\left(y_{r}\right)\right)=u_{b}\left(y_{b}\right)+\beta u_{r}\left(y_{r}\right)
$$

\footnotetext{
${ }^{8}$ Alternatively, we could motivate private transfers from the "warm glow" that giving imparts to benefactors as in Atkinson (1976) and Andreoni (1990). This specification places the transfer itself in the benefactor's utility function so that utility is given by $U_{b}\left(y_{b}, g\right)$. Doing so would not alter any of the results. See Atkinson (1976, p. 15).

${ }^{9}$ See Bernheim and Stark (1988) and Stark (1993) for the argument that symmetric altruism does not completely resolve conflicts between paired agents.
} 
where $y_{b}$ is the benefactor's income, $y_{r}$ is the recipient's income, $u_{r}\left(y_{r}\right)$ is the recipient's utility and $0 \leq \beta \leq 1$ is the altruism factor. We assume that the utility function $u($.$) is identical across agents,$ with $u_{i}^{\prime}>0$ and $u_{i}^{\prime \prime}<0$ for $i=b, r$.

To motivate private transfers, we assume that $y_{b}>y_{r}$, where both are certain. The benefactor decides how much to give to the recipient as a transfer ${ }^{10}$. Her problem can be written as

$$
\max _{g} u_{b}\left(y_{b}-g\right)+\beta u_{r}\left(y_{r}+g\right)
$$

The first order condition is

$$
-u_{b}^{\prime}\left(y_{b}-g\right)+\beta u_{r}^{\prime}\left(y_{r}+g\right)=0
$$

Let $\mathrm{g}$ denote the optimal choice of transfer that results from solving (1).

Now consider the social planner's problem. As in Atkinson (1976), the social planner maximizes an explicit social welfare function. The social planner chooses the transfer that maximizes the following objective:

$$
u_{b}\left(y_{b}-g\right)+(1+\beta) u_{r}\left(y_{r}+g\right) \text {. }
$$

Note that the social planner's objective function double-counts the utility of the recipient in the manner suggested by Stiglitz (1987). The first order condition in this case is

$-u_{b}^{\prime}\left(y_{b}-g\right)+(1+\beta) u_{r}^{\prime}\left(y_{r}+g\right)=0$,

which determines the social planner's optimal transfer, $g_{s p}^{*}$.

Stiglitz and Kaplow have shown that the social planner would choose a larger transfer than the one chosen in a decentralized economy.

Proposition 1 (Stiglitz (1987), Kaplow (1995)): $g_{s p}^{*}>g^{*}$.

Since the social planner would choose a higher transfer than the benefactor chooses, the planner would want to subsidize private transfers. The optimal subsidy is the one that would induce the benefactor to behave like the social planner, with respect to the choice of private transfers.

Suppose that transfers were subsidized at rate $s$, where the subsidy is financed by a lump-sum tax that is taken as given by individuals, as in Kaplow $(1995,1998)$. This reduces the benefactor's cost of making a transfer of size $g$ to $(1-\mathrm{s}) \mathrm{g}$. The first order condition in this case is

\footnotetext{
${ }^{10}$ Our specification assumes that transfers are chosen and distributed before any other outcomes are realized. Delaying the choice and distribution of transfers until after other outcomes are realized strengthens our results by inducing the Samaritan's dilemma. See Buchanan (1975), Bruce and Waldman (1990), and Chami (1996).
} 
$-u_{b}^{\prime}(1-s)+\beta u_{r}^{\prime}=0$.

The subsidy that would induce the benefactor to behave like the social planner is one that would make the benefactor's first order condition (3) equivalent to the social planner's first order condition (2). Solving for this $s$ yields ${ }^{11}$

$$
s^{*}=\frac{u_{r}^{\prime}}{u_{b}^{\prime}}=\frac{1}{1+\beta} \text {. }
$$

Note here that the higher the degree of altruism $\beta$, the lower is the subsidy. That is true because as altruism increases, the benefactors choose to make larger transfers. Altruism leads the benefactor to internalize the consumption externality partially, in the sense that altruism makes the benefactor's private valuation of private transfers approach the social value of private transfers, so a lower subsidy rate is necessary to induce the optimal transfer.

\section{EXOGENOUS UNCERTAINTY}

Now we consider the case in which the benefactor has a certain income but the recipient faces income risk outside his control. Assume that there is an exogenous probability $P$ that the recipient's income is $y_{L}$, whereas with probability $I-P$ the recipient's income is $y_{H}>y_{L}$. The benefactor's motivation for private transfers may be to help insure the recipient against the bad outcome $y_{L}$, which is certainly true in the case of altruism ${ }^{12}$. The recipient's expected utility, allowing for a transfer, is

$$
E U_{r}=P u_{r}\left(y_{L}+g\right)+(1-P) u_{r}\left(y_{H}+g\right) \text {. }
$$

Define $u_{r L} \equiv u_{r}\left(y_{L}+g\right)$, and $u_{r H} \equiv u_{r}\left(y_{H}+g\right)$. It is clear that $u_{r H}>u_{r L}$. The benefactor's utility function, allowing for private transfers, is

$$
U_{b}=u_{b}+\beta E U_{r}=u_{b}\left(y_{b}-g\right)+\beta\left[P u_{r}\left(y_{L}+g\right)+(1-P) u_{r}\left(y_{H}+g\right)\right] \text {, }
$$

and her first order condition is

$$
-u_{b}^{\prime}+\beta\left[P u_{r L}^{\prime}+(1-P) u_{r H}^{\prime}\right]=0 .
$$

The social planner's problem is to choose $g$ to maximize

$$
u_{b}+(1+\beta) E U_{r}=u_{b}\left(y_{b}-g\right)+(1+\beta)\left[P u_{r}\left(y_{L}+g\right)+(1-P) u_{r}\left(y_{H}+g\right)\right] \text {, }
$$

\footnotetext{
${ }^{11}$ See Kaplow (1995).
}

${ }^{12}$ We are assuming here that the benefactor precommits to a fixed transfer of $g$. We could also assume a state-dependent transfer, and doing so would strengthen the results regarding the negative externality. See Chami (1998). 
and the first order condition in this case is

$$
-u_{b}^{\prime}+(1+\beta)\left[P u_{r L}^{\prime}+(1-P) u_{r H}^{\prime}\right]=0 .
$$

Using conditions (4) and (5), we prove a lemma that says that in the case of exogenous uncertainty, the social planner's transfer is greater than that chosen in a decentralized economy.

Lemma 1: $g_{s p}^{*}>g^{*}$.

Proof: Define the function $F(\theta, g)$ as the following:

$$
F(\theta, g) \equiv-u_{b}^{\prime}+\beta\left[P u_{r L}^{\prime}+(1-P) u_{r H}^{\prime}\right]+\theta\left[P u_{r L}^{\prime}+(1-P) u_{r H}^{\prime}\right]=0,
$$

such that if $\theta=1(6)$ reduces to (5), whereas if $\theta=0$ then (6) reduces to (4). Now, $F_{\theta}=P u^{\prime}{ }_{r L}^{+}$ $(1-P) u_{r H}^{\prime}>0$, so $d g / d \theta>0$ by the implicit function theorem, which implies $g_{s p}^{*}>g^{*}$. Q.E.D.

Again the fact that the social planner's transfer is larger than the private transfer implies that we can calculate an optimal subsidy. Subsidizing the benefactor's transfers would again reduce the cost of a transfer to $(1-\mathrm{s}) \mathrm{g}$ so that the first order condition is now

$-(1-s) u_{b}^{\prime}+\beta\left[P u_{r L}^{\prime}+(1-P) u_{r H}^{\prime}\right]=0$.

The optimal subsidy is once again the $s$ that makes the benefactor's first order condition (7) equivalent to the social planner's first order condition (5):

$$
s^{*}=\frac{P u_{r L}^{\prime}+(1-P) u_{r H}^{\prime}}{u_{b}^{\prime}}=\frac{1}{1+\beta} .
$$

Thus, the optimal subsidy in the case where the risk facing the recipient is exogenous is the same as in the certainty case.

\section{ENDOGENOUS RISK}

Now we endogenize the income risk faced by the recipients by making their income depend on the amount of labor effort they choose to expend. We also introduce a labor market with moral hazard into the analysis. Introducing the labor market facilitates the endogenization of income risk, but it also serves an important role in the analysis. The labor market aggregates the effects of recipients' choices and then transmits the results back to the recipients, in the form of wages. We know that private transfers will affect the recipients' choice of effort level, especially when the benefactor cannot observe the recipient's choice of effort, and as a result, cannot contract directly on the desired effort level. While the individual recipient is a price taker, collectively the recipients' actions change the equilibrium wages in the labor market. In particular, in the presence of private transfers, new equilibrium wages will be established that represent a reallocation of risk away from risk-neutral firms and toward the risk-averse recipient-workers (and therefore to the benefactors as well), which is inefficient. In order to correct this inefficiency, a social planner would want to reduce the subsidy given to private transfers or possibly convert it into a tax on private transfers. 
Suppose that the recipients enter the labor market for a single period and supply labor to firms. Output can be high $\left(x_{H}\right)$ or low $\left(x_{L}\right)$. The probability that the low-output state occurs is $P(e)$, where $e$ is the worker's effort, which is unobservable to both the firm and the benefactor; we assume $P^{\prime}<0$ and $P^{\prime \prime}>0$. Wages are $y_{L}$ in state $L$ and $y_{H}$ in state $H$, where $y_{L}<y_{H}$. The difference in wages across states of nature reflects the moral hazard in the labor market. Also, risk aversion on the part of recipients implies that $y_{L}>x_{L}$ and $y_{H}<x_{H}$.

Competitive labor and output markets dictate that $y_{L}$ and $y_{H}$ will maximize expected profits, while competition drives expected profits to zero. Hence

$$
E \pi\left(y_{L}, y_{H} ; e\right)=P(e) x_{L}+(1-P(e)) x_{H}-\left[P(e) y_{L}+(1-P(e)) y_{H}\right]=0 \text {. }
$$

The recipient's expected utility is now

$$
E U_{r}=P u_{r L}+(1-P) u_{r H}-v(e) \text {, }
$$

where $v(e)$ is a strictly convex function reflecting the recipient's disutility of effort, and $u_{r L}, u_{r H}$ are defined as above. The recipient now has a choice to make: he chooses effort to maximize utility. The first order condition for the recipient is

$P^{\prime}\left[u_{r L}-u_{r H}\right]-v^{\prime}(e)=0$,

which gives $e^{*}=e\left(y_{L}, y_{H}, g\right)$.

It is easy to show ${ }^{13}$ that $\partial e^{*} / \partial y_{L}<0$, while $\partial e^{*} / \partial y_{H}>0$. The impact of private transfers on the optimal choice of effort by the recipient is

$$
e_{g}^{*} \equiv \frac{\partial e^{*}}{\partial g}=-\frac{P^{\prime}\left[u_{r L}^{\prime}-u_{r H}^{\prime}\right]}{P^{\prime \prime}\left[u_{r L}-u_{r H}\right]-v^{\prime \prime}(e)}<0 .
$$

Equation (11) shows how private transfers affect the incentives, and hence the choice of effort, of the recipient. The transfer essentially provides insurance against low output, so the recipient lowers the effort he puts into avoiding the low-output state. In other words, the recipient uses the income from the transfer to effectively purchase a reduction in labor effort ${ }^{14}$. This reflects the asymmetric information problem between the benefactor and the recipient.

If instead the model were symmetric in that both the giver and recipient were equally altruistic and both faced the same income risk, then the magnitude of the response of effort to private transfers would be reduced. But the moral hazard would not be eliminated except in the special case of $\beta=I$ for both giver and recipient. In such a case, each agent values the other's utility as

\footnotetext{
${ }^{13}$ Please refer to the Appendix for details.

${ }^{14}$ Holtz-Eakin et al (1993) show in an empirical study that labor supply and labor force participation drop as a result of large inheritances.
} 
his own and completely internalizes the effects of his actions on the other. As a result, the difference in opinion between giver and recipient regarding the optimal level of effort completely disappears and there is no reduction in effort by the recipient as a result of private transfers. So long as $\beta<1$, however, private transfers will reduce effort.

The benefactor's expected utility, $E U_{b}$, is

$$
E U_{b}=u\left(c_{b}\right)+\beta\left[P u_{r L}+(1-P) u_{r H}-v(e)\right],
$$

where $c_{b}=y_{b}-g$ is the benefactor's net consumption, $y_{b}$ is her (exogenous) income, and $g$ is the transfer to her beneficiary. Note that despite the benefactor's altruism, the benefactor and the beneficiary do not see eye to eye on the effort level that the recipient is expected to expend. This is due to the fact that the benefactor discounts the beneficiary's disutility of effort $v(e)$ by $\beta<1$. This problem, furthermore, is exacerbated by the presence of asymmetric information between them, and the inability of the benefactor to contract directly on her desired effort level. The benefactor can only observe the labor market outcome, and infer from it the effort level expended.

The first order condition for the private transfer decision is ${ }^{15}$

$$
-u_{b}^{\prime}+\beta\left\{\left[P^{\prime}\left(u_{r L}-u_{r H}\right)-v^{\prime}\left(e^{*}\right)\right] e_{g}^{*}+\left[P u_{r L}^{\prime}+(1-P) u_{r H}^{\prime}\right]\right\}=0,
$$

and using the envelope condition to substitute out condition (10), the above condition reduces to

$$
-u_{b}^{\prime}+\beta\left[P u_{r i}^{\prime}+(1-P) u^{\prime}{ }_{r H}\right]=0,
$$

which yields $g^{*}=g\left(y_{b}, y_{L}, y_{H} ; e^{*}, \beta\right)$. It is straightforward to show that higher altruism leads to higher transfers, $g_{\beta}^{*}=\partial g^{*} / \partial \beta>0$, and that higher wages in either state lead to lower transfers: $g_{L}^{*}=\partial g^{*} / \partial y_{L}<0$, and $g_{H}^{*} \equiv \partial g^{*} / \partial y_{H}<0^{16}$

We now move to the market reaction to private transfers. So far, we have shown that higher altruism on the part of givers leads to larger transfers, and that larger transfers in turn induce lower labor effort on the part of recipients. We also know that lower effort increases the probability of realizing the low-output state, which in turn leads to lower expected firm profits. One would then expect profit-maximizing firms to react by altering the wage contract they offer. Since expected profits are lower, firms must reduce costs by lowering expected wages. But they must also adjust the relationship between the high wage and low wage, in order to motivate the recipients to put forth higher effort. Given that the expected wage must be lower, we focus our

\footnotetext{
${ }^{15}$ Alternatively, we could choose to make the transfer state-contingent so that it is $g_{L}$ in the low output state and $g_{H}$ in the high output state. Doing so does not affect any of the qualitative results presented below. See, for example, Chami (1998).

${ }^{16}$ Please refer to the Appendix for the details.
} 
analysis on wage dispersion. In other words, given $e^{*}, g^{*}$, and the conditions derived above, we examine the impact of increases in $\beta$ on $y_{H} / y_{L}$.

Firms are willing to pay any combination of wages that satisfies the zero-profit condition. Therefore, the zero-profit condition specifies the relationship between the wages in the two states of nature, or in other words, the dispersion between $y_{L}$ and $y_{H}$. To analyze the impact of altruism on wage dispersion, we differentiate the zero profit condition with respect to $\beta$ :

$$
\frac{d\left[\frac{y_{L}-x_{L}}{x_{H}-y_{H}}\right]}{d \beta}=-\frac{P^{\prime}}{P^{2}} \frac{\partial e^{*}\left(g^{*}(\beta)\right)}{\partial \beta}<0,
$$

where, as we have shown previously, $\partial^{*} / \partial g<0$ while $\partial g^{*} / \partial \beta>0$. Since risk aversion on the part of the recipient implies that $y_{L}>x_{L}$ and $y_{H}<x_{H}$, an increase in $\beta$ moves the state-contingent wages $y_{L}$ and $y_{H}$ further apart. Thus, higher altruism results in lower expected wages and higher wage dispersion. What happens is that private transfers lower work effort, which increases the probability of a bad realization of output. This puts downward pressure on firm profits, which results in the adjustment of $y_{L}$ and $y_{H}$ in order to maintain the zero-profit condition.

The interaction between altruism and the market described above plays an important role in this result. The givers' altruism toward the recipients exacerbates the moral hazard problem that already exists between recipients and firms. In other words, private transfers impose a negative externality on the labor market. Individual benefactors and recipients are price takers, so they do not internalize this effect on the labor market. But the market aggregates their responses to private transfers and thus equilibrium prices and quantities change.

The market responds to the negative externality in private transfers by reallocating risk in a way that is detrimental to the transfer recipients. The increased dispersion between the high wage and the low wage is an increase in the recipient's market income risk. The market has transferred risk from risk-neutral firms to risk-averse individuals, which is inefficient.

We illustrate these welfare effects in Figure 1. Figure 1a depicts the market equilibrium in the absence of private transfers, which is characterized by the moral hazard problem. $U_{r}$ is the recipient's indifference curve, which has slope given by $d y_{H} / d y_{L}=-\left(P u_{L}^{\prime}\right) /\left[(1-P) u_{H}^{\prime}\right]$. Full insurance for the recipient lies along the 45 degree line, where $d y_{H} / d y_{L}=-P /(1-P)$. The wage contract is constrained to lie on the firm's zero-profit line $Z P L_{l}$, whose slope is given by

$$
\frac{d y_{H}}{d y_{L}}=\frac{-P+\left(x_{L}-y_{L}\right) P^{\prime} \frac{\partial e^{*}}{\partial y_{L}}}{1-P+\left(x_{H}-y_{H}\right) P^{\prime} \frac{\partial e^{*}}{\partial y_{H}}}
$$

The equilibrium is found at point $\mathrm{A}$, which is the tangency between $U_{r}$ and $Z P L_{1}$. Because of the moral hazard, the slope of $Z P L_{l}$ at point $\mathrm{A}$ is steeper than $P /(1-P)$, which implies that the recipient is less than fully insured against income risk. The price-taking recipient would therefore 
like to purchase insurance if the price is less than or equal to $P /(I-P)$, and would welcome a transfer because it provides "free" insurance.

As Figure $1 \mathrm{~b}$ shows, however, the market equilibrium with private transfers does not necessarily make the recipient better off. Let point B in Figure $1 \mathrm{~b}$ represent the market equilibrium without private transfers. The introduction of private transfers has two effects on the figure. First, by lowering effort (recall $\hat{\alpha}^{*} / \partial g<0$ ), private transfers increase the recipient's utility at every given wage contract $\left(y_{L}, y_{H}\right)$. This effectively increases the level of utility associated with each indifference curve (or shifts the recipient's indifference map to the left). The second effect is that private transfers decrease firm profits at each given wage contract. As we showed above, the presence of private transfers lowers the recipients' effort, raising the probability of realizing low output in production. The effect on the firm's profitability is represented in Figure $1 \mathrm{~b}$ by shifting the firm's zero-profit line in toward the origin from $Z P L_{1}$ to $Z P L_{2}$. Thus, the contract given by point $\mathrm{B}$ is no longer feasible. Because the zero-profit line has shifted to $Z P L_{2}$, the equilibrium is now at point $\mathrm{C}$. At point $\mathrm{C}$, the wage contract features a higher value of $y_{H}$ and a lower value of $y_{L}$. In other words, risk has been reallocated toward the recipient in the form of higher wage dispersion. The increased risk of the new equilibrium is associated with a lower indifference curve, $U_{r}^{2}$. The move from $U_{r}^{1}$ to $U_{r}^{2}$ is a welfare loss that may offset the welfare gain from the transfer.

As we see next, a social planner would take the change in risk allocation into consideration when choosing the socially optimal transfer. Assume that the social planner chooses $g, y_{L}$, and $y_{H}$ in order to maximize the social objective function

$u_{b}+(1+\beta) E U_{r}$,

subject to

$e$ argmax $E\left(U_{r}\right)$ according to (10),

$\left(y_{L}, y_{H}\right) \operatorname{argmax} \pi$, according to (9).

We are only interested in the planner's choice of transfer. Differentiating the social planner's objective function with respect to the transfer yields ${ }^{17}$

$$
-u_{b}^{\prime}+(1+\beta)\left\{\left(P^{\prime}\left[u_{r L}-u_{r H}\right]-v^{\prime}\left(e^{*}\right)\right) e_{g}^{*}+P u_{r L}^{\prime}\left[1+\frac{\partial y_{L}^{*}}{\partial g}\right]+(1-P) u_{r H}^{\prime}\right\}
$$

where

$\frac{\partial y_{L}^{*}}{\partial g}=-\left(x_{H}-y_{H}\right) \frac{P^{\prime} e_{g}^{*}}{P^{2}}<0$.

${ }^{17}$ See Arnott and Stiglitz (1991) for a similar treatment in the insurance market. 
Now we prove that the social planner chooses a lower transfer in this case, relative to the case in which the risk is exogenous. Let $g_{E}^{*}$ be the optimal transfer that the social planner chooses in condition (5), where risk is exogenous. Then we have the following result:

Proposition 2: $g_{s p}^{*}<g_{E}^{*}$.

Proof: Using equation (10) to substitute the recipient's first order condition out of (13), conditions (5) and (13) can be nested together as

$F(\theta, g) \equiv-u_{b}^{\prime}+(1+\beta)\left[P u_{r L}^{\prime}+(1-P) u_{r H}^{\prime}\right]+\theta(1+\beta) P u_{r L}^{\prime} \frac{\partial y_{L}^{\prime \prime}}{\partial g}=0$,

where $\theta=1$ returns condition (13) and $\theta=0$ returns condition (5). It is clear that

$F_{\theta}=(1+\beta) P u_{r L}^{\prime} \frac{\partial y_{L}^{+}}{\partial g}<0$

which implies that $d g / d \theta<0$. Thus, $g_{s p}^{*}<g_{E}^{*}$. Q.E.D.

The above result is driven by the market's response to the introduction of endogenous risk and the accompanying negative externality. The social planner takes into account the market reaction to the negative externality caused by private transfers, which is the depressive effect of transfers on $y_{L}$. This reaction to the negative externality at least partially offsets the positive externality embodied in the double counting of recipient utility in the social planner's objective function. Thus private transfers are no longer as "blessed" in the social planner's objective, and the optimal transfer is reduced relative to the exogenous uncertainty and perfect foresight cases.

The question raised by this result is how much the welfare effects of the negative externality offset the double counting effect. Which effect dominates?

In order to answer this question, we derive the optimal subsidy in the endogenous risk case. First, we rewrite the social planner's first order condition (13) using the envelope condition to substitute out condition (10). Doing so gives

$$
-u_{b}^{\prime}+(1+\beta)\left[P u_{r L}^{\prime}\left(1+\frac{\partial y_{L}^{*}}{\partial g}\right)+(1-P) u_{r H}^{\prime}\right]=0
$$

We know that due to the moral hazard in the labor market, the recipient is not fully insured, so that $u_{r H}>u_{r L}$ and $(I-P) u_{r H}^{\prime}<P u_{r L}^{\prime}$. We also know that $\partial y_{L}^{*} / \partial g<0$. The benefactor's first order condition for subsidized private transfers is

$-(1-s) u_{b}^{\prime}+\beta\left[P u_{r L}^{\prime}+(1-P) u_{r H}^{\prime}\right]=0$.

Solving for the optimal subsidy using (14) yields 
$s^{*}=\frac{1}{1+\beta}+\beta P \frac{u_{r L}^{\prime}}{u_{b}^{\prime}} \frac{\partial y_{L}^{*}}{\partial g}$.

Note that the optimal subsidy in the endogenous risk case is equal to the subsidy from the exogenous risk case, plus an additional term that is negative. This negative term represents the market response to the negative externality. In the case of exogenous risk, the subsidy fell as $\beta$ increased because less subsidy was needed to obtain the social benefit from the positive externality. In the endogenous risk case, this effect is still present, but the subsidy also falls because as $\beta$ increases, the negative term capturing the market response to the negative externality gets larger also. This directly reduces the size of the optimal transfer, so a lower subsidy is needed to induce it. The interaction of altruism and the response of the market to private transfers will determine whether the optimal subsidy is positive, zero, or negative (a $\operatorname{tax})^{18}$. The higher the level of altruism, and the stronger the market response to private transfers, the lower the subsidy will be.

We wish to emphasize before moving on that the results presented in this study are robust to changes in the specification and timing of the model. As mentioned above, a symmetric model (both in terms of altruism and risk) does reduce the magnitude of $\hat{\partial}^{*} / \partial \mathrm{g}$ in the endogenous risk case, but it does not eliminate this effect unless $\beta=1$. It does not seem likely that even the closest family ties imply this level of altruism. In addition, making the transfers state contingent will not alter the results presented in this paper. Since the giver is altruistic at the margin, the transfer given in the bad state would exceed that given in the good state, which would make the recipient reduce effort ${ }^{19}$.

\section{Calibration and Policy Implications}

A useful way to compare the differing prescriptions for private transfers that arise from this paper is to perform a simple calibration exercise that calculates the size of the optimal subsidy under various parameter values. Figure 2 graphs the optimal subsidy in equation (15) as a function of the altruism parameter $\beta$, for varying choices of the market response to private transfers, $\partial y_{L}{ }_{L} / \partial \mathrm{g}$. Each line in the Figure corresponds to a progressively higher magnitude of $\partial y_{L}^{*} / \partial g$, beginning with the certainty or exogenous risk case of $\partial{ }^{*}{ }_{L} / \partial g=0$, which corresponds to the subsidy calculated by Kaplow (1995).

The remaining parameters $P$ and $u_{r}^{\prime} / u^{\prime}{ }_{b}$, which are held constant over all calculations, were chosen in the following way. The probability of realizing a bad output state was calculated as the average time the U.S. spent in recession relative to time spent in expansion during the period 1945-1996, using the NBER's business cycle dates. This number, about $1 / 6$, represents the

${ }^{18}$ Alternatively, using a social welfare function of the form $u_{b}+E U_{r}$ alters the result in that the subsidy unambiguously becomes a tax.

${ }^{19}$ The moral hazard in private transfers is also exacerbated if the giver's decision is delayed until after the state of nature is revealed. See Chami (1996). 
probability that any given month will be a recessionary month. The ratio of marginal utilities was calculated using the constant relative risk aversion (CRRA) utility function $u(c)=c^{1-\gamma} /(1-\gamma)$ with risk aversion parameter $\gamma$ set equal to four. This value corresponds to estimates in the finance literature and represents a moderate level of risk aversion ${ }^{20}$. The marginal utility of the recipient was calculated assuming a consumption level equal to the 20th percentile of U.S. household income $(\$ 14,768)$, while the marginal utility of the benefactor was calculated assuming a consumption level equal to the median U.S. household income $(\$ 35,492)$. These statistics are from the U.S. Bureau of the Census (1998).

Figure 2 demonstrates the response of the optimal subsidy to the presence of endogenous risk. The uppermost line on the graph represents the certainty or exogenous risk case, in which the subsidy is given by $1 /(1+\beta)$. As the market response to private transfers increases, representing a greater presence of endogenous risk, the optimal subsidy falls further beneath this benchmark. The market response in Figure 2 varies from 0 to -1.25 , with a value of -1.0 indicating that, at the margin, the market reduces the wage in the bad state by one dollar for every dollar of transfer made. The choices of $\partial y_{L}^{*} / \partial g$ are illustrative rather than definitive.

The figure shows that the subsidy function is bounded away from zero for all values of $\beta$ as long as the market response to transfers stays between 0 and -0.5 . But for sufficiently high values of $\beta$ and $\hat{y}_{L}{ }^{*} / \partial$ g, the optimal subsidy does become a tax. Generally speaking, it seems that it would require a very strong market response and a very high degree of altruism for the subsidy to become a $\operatorname{tax}^{21}$. But the optimal subsidy including the market response does decline significantly, relative to the subsidy that ignores the market response. Of course, it is important to keep in mind that the position of the curves depends on the particular values of the probability, consumption, and risk aversion parameters discussed above. All of the underlying parameters, including the labor market response to private transfers and the level of altruism, should be carefully estimated before choosing an appropriate subsidy for private transfers.

\section{CONCLUSION}

As developed nations as well as developing economies such as Chile and Argentina search for more cost-effective social insurance systems, government subsidies for private transfers should be considered as a supplement or an alternative to direct government provision of social insurance. In this paper, we have developed a framework for evaluating the subsidized private transfers option. Our framework incorporates the full welfare effects of private transfers, which include the impact on welfare of the market's reaction to private transfers. This enables us to measure the net benefit of subsidies on private transfers more accurately. We show that although

${ }^{20}$ Given a risk-aversion parameter of 4 , the median-income household would value a 50-50 gamble with payoffs of $\$ 0$ and $\$ 1000$ at $\$ 486.11$. A risk-neutral household would value the gamble at its expected value of $\$ 500$.

${ }^{21}$ Large gifts from parents to children (over $\$ 10,000$ per year) are taxed in the US. Perhaps this is a special case in which the altruism level is high enough, and the market response great enough, to justify such a tax. 
private transfers enhance welfare by inducing a positive consumption externality, they also create a negative externality, causing a market response that reduces welfare. The negative externality offsets the positive consumption externality, but probably only partially, which implies that a positive optimal subsidy exists. We derive the optimal subsidy and show the key linkages that must be estimated in order to calculate the optimal subsidy in practice. We hope that by presenting a richer analytical framework for private transfers, we will stimulate a serious debate on the feasibility and desirability of using subsidies and private charities to replace welfare programs. In our opinion, this alternative has received too little attention from policymakers and economists.

Our enthusiasm for subsidized private transfers is tempered by the moral hazard in private transfers that is the focus of this paper. We show that the moral hazard problem in private transfers leads to lower work effort, lower profits, and hence worse labor market outcomes. These are also the effects of government-provided social insurance, which have been well documented. Thus, the replacement of government social insurance through subsidized private transfers may not represent a large enough increase in overall welfare to justify the expense of changing the system over. If, on the other hand, it could be shown that private groups such as NGOs, religious societies, or unions can reduce the moral hazard problem, then subsidized private transfers may well represent a significant increase in social welfare.

Private institutions have devised mechanisms to mitigate the moral hazard problem in private transfers. Arnott and Stiglitz (1991) suggest "peer monitoring" in the context of insurance markets, in which pairs or groups of insured agents with a common bond such as marriage or family ties observe each other's actions at a lower cost than an insurance company does. Beito (2000) studies successful instances of private, market-based social insurance among groups who have common bonds of the kind that facilitate peer monitoring, such as mutual-aid societies and unions ${ }^{22}$. There are cases in which this practice has been implemented in private transfers as well. Habitat for Humanity, for example, uses peer monitoring to screen potential aid recipients and to monitor recipients after they have received aid transfers. Monitoring in general may be less costly for NGOs and other private groups than for government agencies. It is probably a necessity for those NGOs that face greater demand for their services than they can afford to provide.

Another mechanism that NGOs may use is trust between givers (or their agents, in the case of charitable transfers) and recipients. We believe that symmetric and reciprocal altruism between two individuals is a useful model of trust. In Section 5, we briefly discussed the effects of symmetric altruism between benefactors and recipients. When trust exists in the form of symmetric, reciprocal altruism, the benefactor and recipient internalize the impact of their actions on the other person's utility. The degree of internalization depends on the size of the altruism parameter, which can be interpreted as a varying degree of trust with $\beta=1$ implying complete trust and hence complete internalization. The more the recipient internalizes the effect of his actions on the benefactor, the less he reduces his effort in response to receiving a transfer.

${ }^{22}$ Recently, Cox (1999) has shown that there may be limits on the size of groups that may successfully coinsure. 
In this way, the negative externality is mitigated by the presence of trust. In addition, there is less need for the benefactor to monitor the recipient when trust exists. For both of these reasons, trust between benefactors and recipients is an effective tool for reducing the moral hazard problem in private transfers. Trust may give NGOs a comparative advantage over government agencies in delivering social insurance resources.

The formation of trust is not well understood, however. Individuals appear to build up trust between one another, but this process has not been modeled. Since NGOs are generally founded to embody altruistic tendencies, it is likely that they attempt to promote trust between NGO staff and the clients they serve. Private charities may have opportunities or the ability to invest in trust between benefactors and recipients that government social insurance agencies lack. Modeling the formation of trust and studying the role of trust in NGOs will provide more evidence on whether NGOs are able to mitigate the moral hazard in private transfers. This is an important task for future research. 
$-20-$

Figure Ia. Market Equilibrium With Moral Hazard

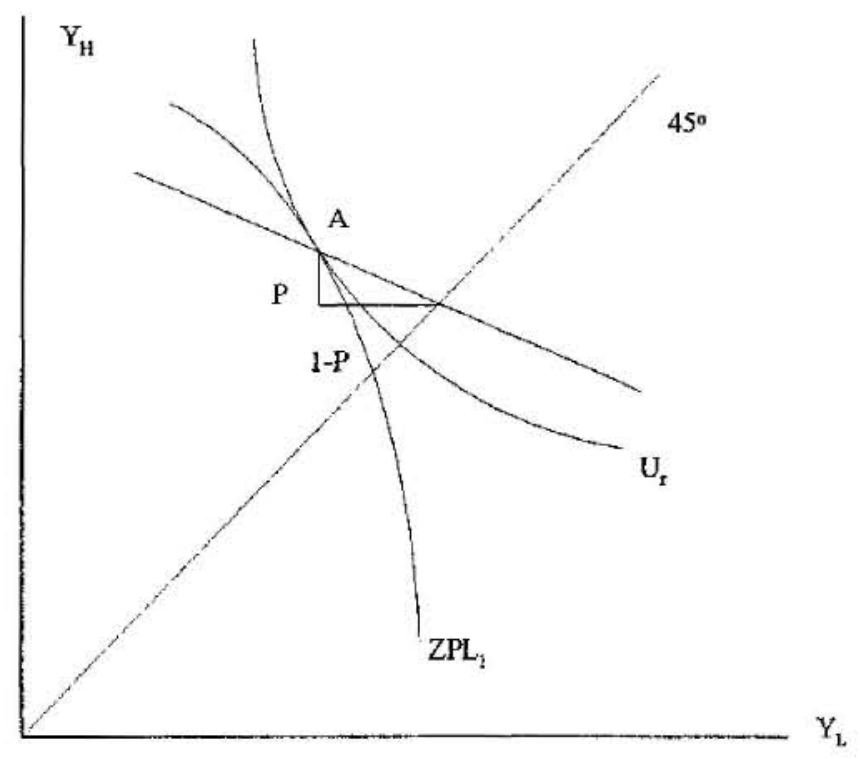

Figure lb. Market Equilibrium With Gift Giving

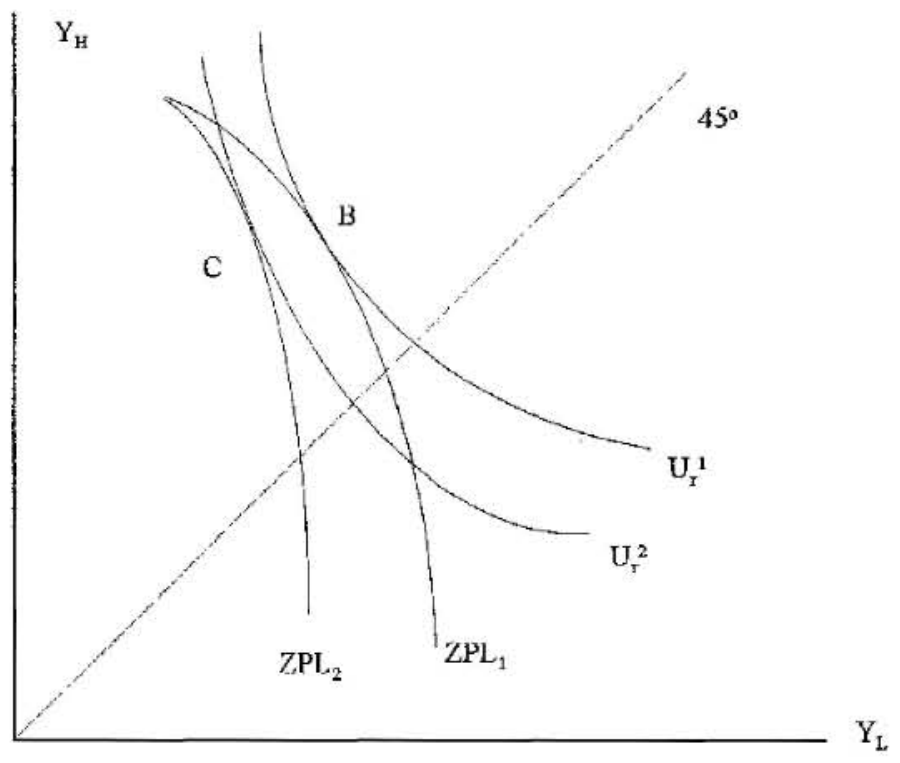




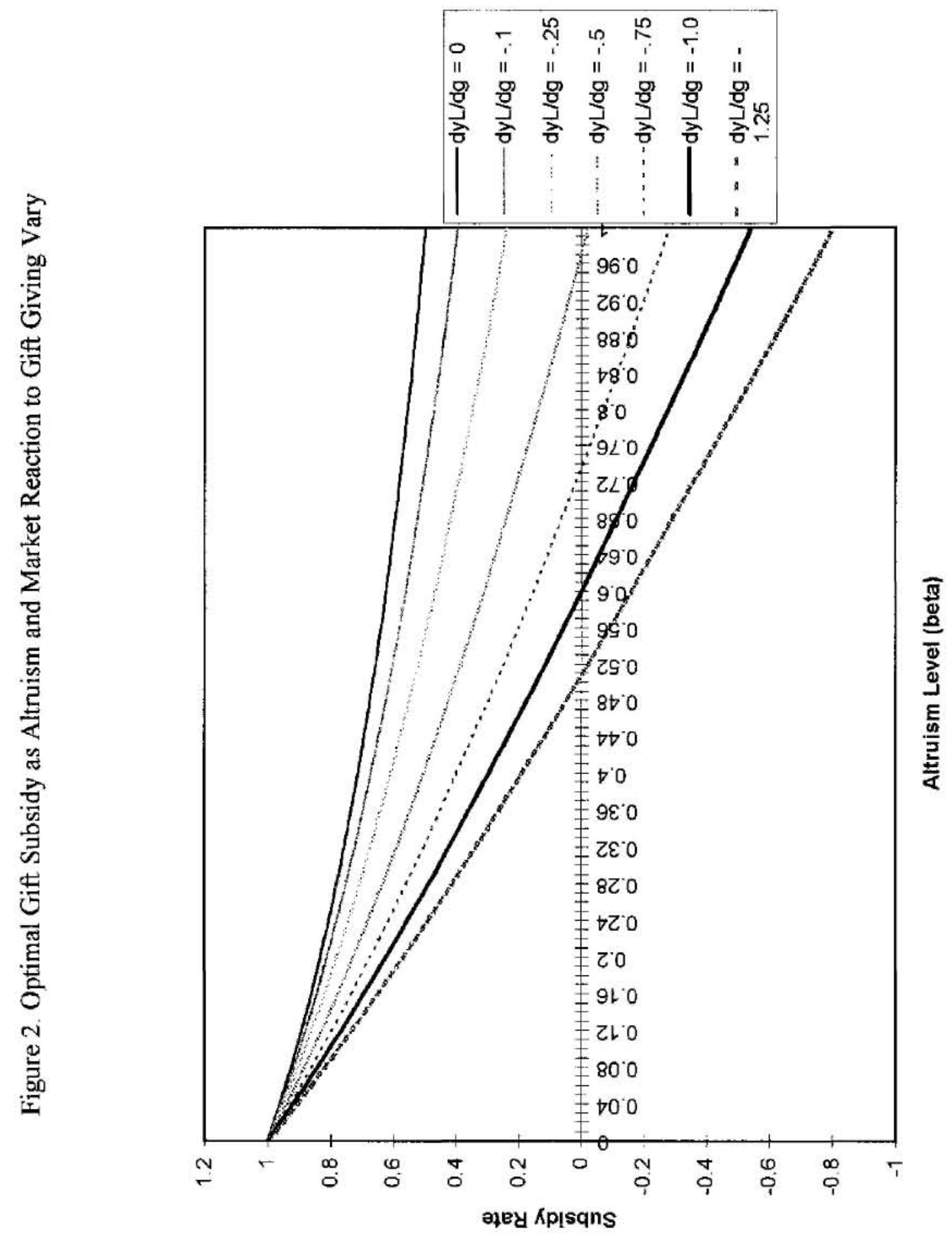


This Appendix derives and signs the partial derivatives governing the responses of effort and transfers mentioned in the text.

\section{A.1 Effort}

From the first-order condition for the recipient, equation (10), we obtain

$$
\begin{gathered}
e_{g}^{*} \equiv e_{1}^{*} \equiv \frac{\partial e^{*}}{\partial g}=-\frac{\left(u_{r L}^{\prime}-u_{r H}^{\prime}\right) P^{\prime}}{\left(u_{r L}-u_{r H}\right) P^{\prime \prime}-v^{\prime \prime}}<0 \\
e_{2}^{*} \equiv \frac{\partial e^{*}}{\partial y_{L}}=-\frac{u_{r L}^{\prime} P^{\prime}}{\left(u_{r L}-u_{r H}\right) P^{\prime \prime}-v^{\prime \prime}}<0 \\
e_{3}^{*} \equiv \frac{\partial e^{*}}{\partial y_{H}}=-\frac{-u_{r H}^{\prime} P^{\prime}}{\left(u_{r L}-u_{r H}\right) P^{\prime \prime}-v^{\prime \prime}}>0 .
\end{gathered}
$$

\section{A.2 Private Transfers}

To find the derivatives of private transfers with respect to altruism and wages, we first find and sign the denominator of the partial derivatives. Writing out the second order condition for the benefactor's choice of transfer gives

$$
\Delta \equiv \frac{\partial^{2} E U_{b}}{(\partial g)^{2}}=u^{\prime \prime}{ }_{b}+\beta\left\{p^{\prime}\left(e^{*}\right)\left[u_{r L}^{\prime}-u_{r H}^{\prime}\right] e_{1}^{*}+P\left(e^{*}\right)\left[\beta u^{\prime \prime}{ }_{r L}\right]+\left(1-P\left(e^{*}\right)\right)\left[\beta u^{\prime \prime}{ }_{r H}\right]\right\}
$$

Rearranging terms, we have

$$
\frac{\partial^{2} E U_{b}}{(\partial g)^{2}}=\beta P u_{r L}^{\prime}\left\{\frac{P^{\prime} e_{1}^{*}}{P}+\frac{u^{\prime \prime}{ }_{r L}}{u_{r L}^{\prime}}\right\}-P^{\prime} e_{1}^{*} u_{r H}^{\prime}+u^{\prime \prime}{ }_{b}+\beta(1-P) u^{\prime \prime}{ }_{r H} .
$$

Note that all the terms save the one in braces are negative. Thus, a sufficient condition for the concavity of the benefactor's surplus function is

\section{Assumption 1:}

$$
\frac{-u^{\prime \prime}{ }_{r L}}{u_{r L}^{\prime}}>\frac{P^{\prime} e_{i}^{*}}{P}, \text { where } i=1,2 .
$$

The above assumption implies that a sufficient condition for an interior solution to the benefactor's problem is that the beneficiary be sufficiently risk averse, such that the direct impact of a change in his wealth on his marginal utility of income, in the bad state, exceeds the indirect impact of wealth on the probability of a low output occurring through its effect on the beneficiary's effort. 
To sign the derivative of $g^{*}$ with respect to $\beta$, differentiate the first-order condition for the benefactor (12):

$$
\frac{d g^{*}}{d \beta}=\frac{-\left[P u_{r L}^{\prime}+(1-P) u_{r H}^{\prime}\right]}{\Delta}>0 .
$$

Similarly, for the derivative of $g^{*}$ with respect to $y_{H}$, we have

$$
\frac{\partial g^{*}}{\partial y_{H}}=\frac{-\beta\left[(1-P) u^{\prime \prime}{ }_{r H}+\left(u_{r L}^{\prime}-u_{r H}^{\prime}\right) P^{\prime} e_{3}^{*}\right]}{\Delta}<0 .
$$

Finally, for the derivative of $g^{*}$ with respect to $y_{L}$, we have, using the above concavity assumption,

$$
\frac{\partial g^{*}}{\partial y_{L}}=\frac{-\beta\left[P u^{\prime \prime}{ }_{r L}+\left(u_{r L}^{\prime}-u_{r H}^{\prime}\right) P^{\prime} e_{2}^{*}\right]}{\Delta}<0 .
$$




\section{REFERENCES}

Andreoni, James, 1988, "Privately Provided Public Goods in a Large Economy: The Limits of Altruism," Journal of Public Economics Vol. 35, pp. 57-73.

- 1990, "Impure Altruism and Donations to Public Goods: A Theory of Warm-Glow Giving," Economic Journal, Vol. 100, pp. 464477.

Arnott, Richard, and Joseph E. Stiglitz, 1991, "Moral Hazard and Nonmarket Institutions: Dysfunctional Crowing Out or Peer Monitoring?" American Economic Review, Vol. 81, pp. $179-89$.

Atkinson, Anthony B., 1976, "The Income Tax Treatment of Charitable Contributions," in Public and Urban Economics: Essays in Honor of William S. Vickery ed. by R. E. Grieson, pp. 13-29 (D.C. Health, New York).

Beito, David T., 2000, From Mutual Aid to the Welfare State (Chapel Hill: University of North Carolina).

Bernheim, B. Douglas, and Oded Stark, 1988, "Altruism Within the Family Reconsidered: Do Nice Guys Finish Last?" American Economic Review, Vol. 78, pp. 1034-1045.

Bruce, Neil, and Michael Waldman, 1990, "The Rotten Kid Theorem Meets the Samaritan's Dilemma," Quarterly Journal of Economics, Vol. 105, pp. 155-65.

_- 1991, "Transfers in Kind: Why They Can Be Efficient and Nonpaternalistic," American Economic Review, Vol. 81, pp. 1345--51.

Buchanan, James M., (1975), "The Samaritan's Dilemma," in Altruism, Morality and Economic Theory, ed. by Edmund S. Phelps (New York: Russell Sage Foundation).

Chami, Ralph, 1996, "King Lear's Dilemma: Precommitment Versus the Last Word," Economics Letters, Vol. 52, pp.171-176.

— , 1998, "Private Income Transfers and Market Incentives," Economica, Vol. 65, pp. 557-580.

Coate, Stephen, 1995, "Altruism, the Samaritan's Dilemma, and Government Transfer Policy," American Economic Review, Vol. 85, pp. 46-57.

Cox, Donald, 1999, "Informal Networks, Institutions and the 'Soap Opera' Constraint," Working Paper, Boston College.

Cutler, David M., and Jonathan Gruber, 1996, "Does Public Insurance Crowd Out Private Insurance?" Quarterly Journal of Economics, Vol. 111, pp. 391-430. 
Friedman, David, 1988, "Does Altruism Produce Efficient Outcomes? Marshall Versus Kaldor," Journal of Legal Studies, Vol. 17, pp. 1-13.

Holtz-Eakin, Douglas, David Joulfaian, and Harvey S. Rosen, 1993: "The Carnegie Conjecture: Some Empirical Evidence," Quarterly Journal of Economics, Vol. 108, pp. 413-35.

Kaplow, Louis, 1998, "Tax Policy and Gifts," American Economic Review, Vol. 88, pp. 283-292.

- 1995, "A Note on Subsidizing Gifts," Journal of Public Economics, Vol. 58, pp. $469-477$.

Kopits, George, 1997, “Are Europe's Social Security Finances Compatible with EMU?" International Monetary Fund Working Paper PPAA/97/3.

Stark, Oded, 1993. "Nonmarket Transfers and Altruism," European Economic Review, Vol. 37, pp. 1413-1424.

Stiglitz, Joseph E., 1987, "Pareto Efficient and Optimal Taxation and the New Welfare Economics," in: Handbook of Public Economics Vol. II, ed. by A. J. Auerbac and M. Feldstein (North Holland, Amsterdam).

Tanzi, Vito, 2000, "Globalization and the Future of Social Protection," International Monetary Fund Working Paper WP/00/12. 